\title{
Stepwise partially overlapping primer-based PCR for genome walking
}

\author{
Kunpeng Chang ${ }^{1}$, Qiong Wang ${ }^{1}$, Xiaofei Shi ${ }^{2}$, Shuixing Wang ${ }^{1}$, Hongjing Wu ${ }^{1}$, Lijuan Nie ${ }^{1}$ and Haixing Li $^{1 *}$
}

\begin{abstract}
A stepwise partially overlapping primer-based PCR (SWPOP-PCR) method for isolating flanking unknown DNA regions was developed, which comprises three rounds of nested PCRs sequentially driven by SWPOP primer-nested specific primer pairs. SWPOP primer set is characterized by a partial overlap of $10 \mathrm{bp}$ with $3^{\prime}$-part of the latter primer is identical to $5^{\prime}$-part of the former one, which makes the SWPOP primer in use anneal to SWPOP site of the prior PCR product only at relatively low temperature. For each PCR, target single-stranded DNA primed by the SWPOP primer in the exclusive one low-stringency cycle is converted into double-stranded form in the following high-stringency cycle due to the presence of a perfect annealing site for the specific primer. This double-stranded DNA bounded by the specific primer and the SWPOP primer is exponentially amplified in the remaining high-stringency cycles. Non-target singlestranded DNA, however, cannot be amplified given the lack of perfect complementary sequences for any primers. Therefore, the partial overlap of a SWPOP primer set preferentially synthesizes target products but inhibits nonspecific amplification. We successfully exploited SWPOP-PCR to obtain the DNA sequences flanking glutamate decarboxylase gene (gadA) locus in Lactobacillus brevis NCL912 and hygromycin gene (hyg) integrated in rice.
\end{abstract}

Keywords: Partially overlapping primer, PCR, Genome walking, gadA locus, hyg

\section{Introduction}

Numerous PCR-based genome walking methodologies have been developed for identification and isolation of neighboring unknown DNA sequences adjacent to known genomic regions, which can be classified into three main categories (Kotik 2009; Leoni et al. 2011): (I) inverse PCR (Ochman et al. 1988); (II) ligation mediated PCR (Mueller and Wold 1989; Arnold and Hodgson 1991; Jones and Winistorfer 1992; Yan et al. 2003; Ji and Braam 2010); and (III) randomly primed PCR (Liu and Whittier 1995; Tan et al. 2005; Wang et al. 2013). The first two categories rely on labor-intensive and time-consuming restriction digestion and ligation of genomic DNA before PCR amplification (Rosenthal and Jones 1990; Acevedo et al. 2008; Leoni et al. 2008, 2010; Trinh et al. 2012b; Spalinskas et al. 2013). In addition, requirements of highquality genomic DNA and several different restriction

\footnotetext{
*Correspondence: hxli@ncu.edu.cn

${ }^{1}$ State Key Laboratory of Food Science and Technology, Sino-German Joint Research Institute, Nanchang University, Nanchang 330047, Jiangxi, China

Full list of author information is available at the end of the article
}

enzymes limit the actual utilization of these methods (Iwahana et al. 1994; Tsuchiya et al. 2009; Bae and Sohn 2010; Trinh et al. 2012a). The third category requires no complicated DNA manipulations before or after PCR (Liu and Chen 2007; Luo et al. 2011). However, the excessive accumulation of non-target DNA products as a consequence of nonspecific annealing of arbitrary primer is the major limitation of these methods (Terauchi and Kahl 2000; Reddy et al. 2008; Thirulogachandar et al. 2011).

Recently, we developed a partially overlapping primerbased PCR (POP-PCR) method for genome walking, which employed a set of POP primers having identical $3^{\prime}$ ends of $10 \mathrm{bp}$ to suppress the amplification of non-target products while effectively enrich the target molecules. However, a separate POP primer has to be used in each round of nested POP-PCR, which contributes to the complexity of experimental operation thus prone to error (Li et al. 2015). Here, we present a novel genome walking strategy, termed stepwise partially overlapping primerbased PCR (SWPOP-PCR), which is easier to operate and more economical than the conventional POP-PCR. The feasibility of the new method was tested by retrieving 
segments of interest from the genomic DNA of L. brevis NCL912 and rice.

\section{Materials and methods}

Genomic DNA isolation and purification

The genomic DNA of L. brevis NCL912 (=CCTCCM208054) was isolated with the TIANamp Bacteria DNA Kit (Tiangen Biotech Co., Ltd, Beijing, China) according to the manufacturer's instructions. Rice genomic DNA was kindly provided by Dr. Shaobo Li (Nanchang University).

\section{Oligonucleotide primers}

The primers used in this study are summarized in Table 1. We designed four sets of SWPOP primer, and each set consists of three primers [SWPOP-P (primary PCR), SWPOP-S (secondary PCR), SWPOP-T (tertiary PCR)] in which $10 \mathrm{bp}$ in $3^{\prime}$-part of the latter primer is identical to $10 \mathrm{bp}$ of $5^{\prime}$-part of the former one. A gene-specific primer set consists of three nested primers [SP-P (primary PCR), SP-S (secondary PCR), SP-T (tertiary PCR)], which were designed based on the DNA sequences of glutamate decarboxylase gene $(\operatorname{gad} A)$ locus (GenBank accession number JX074764) of L. brevis NCL912 (Li et al. 2013) and hygromycin gene (hyg) (KF206149.1) integrated in the genome of rice, respectively. Each specific primer had a similar melting temperature $\left(\mathrm{T}_{\mathrm{m}}\right)$ with its paired SWPOP primer. Other rules in the design of primers were generally the same as those for normal PCR.

\section{PCR procedure}

Three rounds of PCR (primary, secondary, tertiary) were carried out in each walking process using the previous PCR product as the template of the subsequent PCR. A specific primer was paired with its corresponding
SWPOP primer(s) in each round of PCR. In the primary PCR reaction, the $50 \mu \mathrm{L}$ reaction mixture contained $1 \times$ LA PCR buffer II $\left(\mathrm{Mg}^{2+}\right.$ plus), $400 \mu \mathrm{M}$ of each dNTP, $0.2 \mu \mathrm{M}$ of each primer, template DNA (10-100 ng for $L$. brevis NCL912 and 100-1000 ng for rice), and $2.5 \mathrm{U}$ of TaKaRa LA Taq HS. In the secondary/tertiary PCR reaction, the $50 \mu \mathrm{L}$ reaction mixture included $1 \times \mathrm{LA}$ PCR buffer II $\left(\mathrm{Mg}^{2+}\right.$ plus), $400 \mu \mathrm{M}$ of each dNTP, $0.2 \mu \mathrm{M}$ of each primer, $1 \mu \mathrm{L}$ of the previous round of PCR products, and $2.5 \mathrm{U}$ of TaKaRa LA Taq HS.

Each round of PCR contained three annealing stages: stage 1 , five high-stringency $\left(65^{\circ} \mathrm{C}\right)$ cycles; stage 2 , one low-stringency $\left(25{ }^{\circ} \mathrm{C}\right)$ cycle in primary PCR or one reduced-stringency $\left(50{ }^{\circ} \mathrm{C}\right)$ cycle in secondary/tertiary PCR; and stage 3 , twenty-five high-stringency $\left(65^{\circ} \mathrm{C}\right)$ cycles. Reaction profiles of the three rounds of PCR are presented in Table 2.

\section{DNA manipulation and sequencing}

PCR products were purified with the MiniBEST Agarose Gel DNA Extraction Kit Ver.4.0 (TaKaRa, Dalian, China), and were directly sequenced by Sangon Biotech Co., Ltd. (Shanghai, China).

\section{Results \\ Overview of stepwise partially overlapping primer-based PCR}

The outline of SWPOP-PCR is illustrated in Fig. 1. SWPOP-PCR involves three successively nested PCRs. The key point of this strategy is to design a set of stepwise partially overlapping primers in which $3^{\prime}$-part (10 bp) of the latter SWPOP primer is identical to $5^{\prime}$-part of the former one, hence annealing between the SWPOP primer and its partially complementary site (prior SWPOP site) only occur at relatively low temperature. In the initial five high-stringency cycles (HSCs),

Table 1 Primers used in this study

\begin{tabular}{|c|c|c|c|}
\hline \multirow[t]{2}{*}{ Primer set } & \multirow{2}{*}{$\begin{array}{l}\text { Stepwise partially overlapping } \\
\text { primer set (SWPOP primer set) }\end{array}$} & \multicolumn{2}{|l|}{ Specific primer set (SP primer set) ${ }^{a}$} \\
\hline & & gadA locus & hyg \\
\hline \multirow[t]{4}{*}{ Primary PCR } & CAGTCAGTCTCAGCTAGTCAGTGTC & \multirow{4}{*}{$\begin{array}{l}\text { TCCATACCCTCATCTCCATTTCCAT } \\
(-1 \text { to }-25)\end{array}$} & \multirow{4}{*}{$\begin{array}{l}\text { CGGCAATTTCGATGATGCAGCTTGG } \\
(-1 \text { to }-25)\end{array}$} \\
\hline & CAGTCAGTCTCGTCAGTCGTGCAGT & & \\
\hline & CAGTCAGTCTCCACGTCACCAGTCA & & \\
\hline & $\underline{\text { CAGTCAGTCTAGCAGCAGTCGTCAG }}$ & & \\
\hline $\begin{array}{l}\text { Secondary } \\
\text { PCR }\end{array}$ & CAGCACTCACGTAGTCAGTCAGTCT & $\begin{array}{l}\text { AACTATCACCCCACAACGTCATCTC } \\
(-157 \text { to }-181)\end{array}$ & $\begin{array}{l}\text { CGGGACTGTCGGGCGTACACAAATC } \\
(-64 \text { to }-88)\end{array}$ \\
\hline Tertiary PCR & TCAGTACGGTCACCTCAGCACTCAC & $\begin{array}{l}\text { ACCGTTCATAGGCGAAATTGTTTGT } \\
(-335 \text { to }-359)\end{array}$ & $\begin{array}{l}\text { GACCGATGGCTGTGTAGAAGTACTC } \\
(-112 \text { to }-136)\end{array}$ \\
\hline
\end{tabular}

Four SWPOP-P primers were respectively paired with a specific primer for primary PCR; in the subsequent secondary or tertiary PCR, the SWPOP primer and a corresponding specific primer in the same row were matched. The partial identical sequences of SWPOP primers were underlined

a The bracketed numerical ranges below specific primers refer to coordinates in the known DNA sequences (a first base at the $5^{\prime}$-end of an outermost specific primer is defined as-1) 
Table 2 Thermal cycling parameters used in SWPOP-PCR method

\begin{tabular}{|c|c|c|c|}
\hline Round of PCR & Stage & Thermal condition & Cycle number \\
\hline \multirow[t]{5}{*}{ Primary } & & $94^{\circ} \mathrm{C} 2 \mathrm{~min}$ & 1 \\
\hline & 1 & $94^{\circ} \mathrm{C} 30 \mathrm{~s}, 65^{\circ} \mathrm{C} 1 \mathrm{~min}, 72^{\circ} \mathrm{C} 2 \mathrm{~min}$ & 5 \\
\hline & 2 & $94^{\circ} \mathrm{C} 30 \mathrm{~s}, 25^{\circ} \mathrm{C} 1 \mathrm{~min}, 72^{\circ} \mathrm{C} 2 \mathrm{~min}$ & 1 \\
\hline & 3 & $94^{\circ} \mathrm{C} 30 \mathrm{~s}, 65^{\circ} \mathrm{C} 1 \mathrm{~min}, 72^{\circ} \mathrm{C} 2 \mathrm{~min}$ & 25 \\
\hline & & $72{ }^{\circ} \mathrm{C} 5 \min$ & 1 \\
\hline \multicolumn{4}{|c|}{$1 \mu \mathrm{L}$ of the product was directly used as plate in the secondary round of PCR } \\
\hline \multirow[t]{5}{*}{ Secondary } & & $94^{\circ} \mathrm{C} 2 \mathrm{~min}$ & 1 \\
\hline & 1 & $94^{\circ} \mathrm{C} 30 \mathrm{~s}, 65^{\circ} \mathrm{C} 1 \mathrm{~min}, 72^{\circ} \mathrm{C} 2 \mathrm{~min}$ & 5 \\
\hline & 2 & $94^{\circ} \mathrm{C} 30 \mathrm{~s}, 50^{\circ} \mathrm{C} 1 \mathrm{~min}, 72^{\circ} \mathrm{C} 2 \mathrm{~min}$ & 1 \\
\hline & 3 & $94^{\circ} \mathrm{C} 30 \mathrm{~s}, 65^{\circ} \mathrm{C} 1 \mathrm{~min}, 72^{\circ} \mathrm{C} 2 \mathrm{~min}$ & 25 \\
\hline & & $72{ }^{\circ} \mathrm{C} 5 \mathrm{~min}$ & 1 \\
\hline \multicolumn{4}{|c|}{$1 \mu \mathrm{L}$ of the product was directly used as plate in the tertiary round of PCR } \\
\hline Tertiary & Reactio & & \\
\hline
\end{tabular}

the SP primer (specific primer) annealed to its complementary site within the known sequence and extended towards the unknown region, thus increased the copy number of single-stranded DNAs (ssDNAs) of interest with different length (Deng et al. 2010). The subsequent low-stringency cycle (LSC)/reduced-stringency cycle (RSC) allowed SWPOP primer (walking primer) to create annealing site(s) adapted for its $3^{\prime}$-end/bind to the former SWPOP site(s) and extend within the genomic DNA or the previously generated ssDNAs of interest, newly producing a pool of ssDNAs consisting of non-target and target fragments with SWPOP primer sequence at the $5^{\prime}$-ends, among which the target ssDNAs contained SP primer complementary sequence at the $3^{\prime}$-ends whereas the non-target ssDNAs had no perfect annealing sites for the both primers. A nascent target ssDNA was converted into double-stranded molecule bound by the both primers attributed to the presence of SP primer complementary sequence at the $3^{\prime}$-end in the following HSC, rather a non-target ssDNA could not be formed into doublestrand ascribable to the absence of annealing sites for any primers. Therefore, the target molecule but not the nontarget DNA was exponentially amplified equivalently to a specific PCR in the remaining HSCs.

\section{Genome walking of the gadA locus in L. brevis NCL912 and hyg integrated in rice}

To confirm the validity of SWPOP-PCR, we employed the method to isolate target segments flanking the regions of gadA locus in L. brevis NCL912 and hyg integrated in rice. As shown in Fig. 2, four sets of parallel PCR reactions were successfully performed for each DNA sample, respectively. One or more clear predominant DNA band(s) appeared after the secondary and tertiary PCR reactions. A flanking region of approximate $1.2-1.6 \mathrm{~kb}$ in size was uncovered in each walking. Sequencing the bands in the tertiary PCRs showed that the obtained sequences were completely overlapped with the ends of the known gene region. In some cases, more than one target DNA bands suggested that a SWPOP-P primer annealed to multiple sites of a DNA plate.

We also sequenced the distinct DNA bands appeared in the secondary PCRs, and the results confirmed that all those distinct bands were target products. In most cases, a DNA band in secondary PCR was a little larger than that in the corresponding tertiary PCR in size due to the application of nested specific primers (Liu and Whittier 1995).

\section{Discussion}

The key to the success of the proposed method is to have a possible annealing site in the unknown DNA sequence for SWPOP-P primer (SWPOP primer for primary PCR). In our PCR method, a SWPOP-P primer should find an adapted site in the plate given the fact that one super low-stringency $\left(25^{\circ} \mathrm{C}\right)$ cycle was performed in primary PCR. To increase the success rate in genomic walking, we designed four parallel SWPOP-P primers having heterologous $15 \mathrm{bp}$ at the $3^{\prime}$-parts and identical $10 \mathrm{bp}$ at the $5^{\prime}$-parts. The four heterologous $3^{\prime}$-parts are expected to guarantee at least one SWPOP-P primer creates an annealing site adapted for this SWPOP-P within genomic DNA (Parker et al. 1991; Parks et al. 1991).

In the traditional POP-PCR, three POP primers of each POP primer set have uniquely homologous $3^{\prime}$-parts and completely heterologous $5^{\prime}$-parts, thus four POP primer sets include $(4 \times 3)$ twelve primers ( $\mathrm{Li}$ et al. 2015). In SWPOP-PCR, given that the $10 \mathrm{bp} 5^{\prime}$-parts of the four SWPOP-P primers are identical, we designed only one SWPOP-S primer (for secondary PCR) with $10 \mathrm{bp}$ of its 


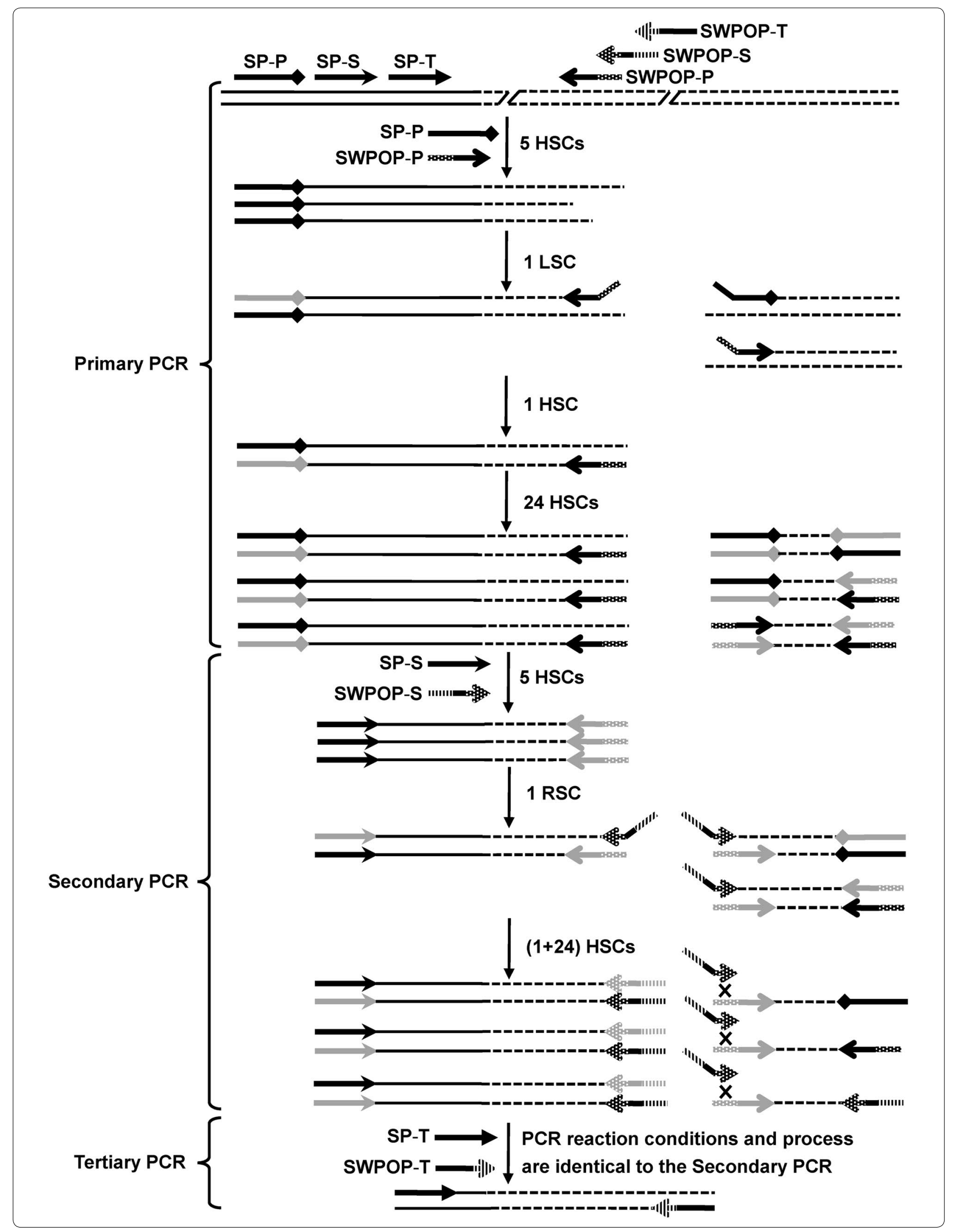


(See figure on previous page.)

Fig. 1 Outline of stepwise partially overlapping primer-based PCR. The first five high-stringency cycles (HSCs) of each PCR were carried out to increase the copy number of specific single-stranded DNA (ssDNA) of interest with different length. The one low-stringency cycle (LSC) of primary PCR allowed SWPOP-P to anneal to the target DNA and extend towards SP-P. The one reduced-stringency cycle (RSC) of secondary/tertiary PCR allowed SWPOP-S/SWPOP-T to bind to the prior SWPOP complementary site(s). A double-stranded target DNA molecule was obtained in the first HSC following LSC/RSC, and served as the template for the remaining twenty-four HSCs. Non-target amplification was suppressed because the double-stranded form could not be synthesized from a non-target single strand. Drawings on the right side: potential nonspecific (non-target) amplifications; SP-P, SP-S, and SP-T: specific primer for primary, secondary, and tertiary PCR, respectively; SWPOP-P, SWPOP-S, and SWPOP-T: stepwise partially overlapping primer for primary, secondary, and tertiary PCR, respectively; solid lines: the known sequence; dotted lines: the unknown sequence; grey arrows: primers complementary sites

$3^{\prime}$-part identical to the $5^{\prime}$-ends of all the four SWPOP-P primers, and automatically only one SWPOP-T primer (for tertiary PCR) with $10 \mathrm{bp}$ of its $3^{\prime}$-part identical to the $5^{\prime}$-part of SWPOP-S primer. Therefore, four SWPOP primer sets contain only $(4+1+1)$ six primers. Moreover, we could make mix master for secondary/tertiary SWPOP-PCRs due to the reaction reagents are the same except for the DNA plate. In addition, two rounds of PCR are sufficient to obtain satisfactory results, so the tertiary SWPOP-PCR can be omitted generally.

In genome walking methods using unspecific (walking) primers, three types of non-target products could be produced: (I) those primed by specific primer alone, (II) those primed by both specific primer and walking primer, and (III) those primed by walking primer alone (Arnold and Hodgson 1991; Bae and Sohn 2010; Wang et al. 2011). Types I and II non-target products could be easily excluded in the following nested PCR given the fact that an inner nested specific primer was used (Yan et al. 2003; Tan et al. 2005; Wang et al. 2007). The common problem faced by all these PCR techniques is how to get rid of type III nonspecific products (Liu and Whittier
1995; Deng et al. 2010; Thirulogachandar et al. 2011), which has limited the application of the existing genome walking methods. We herein use the arbitrary primer (walking primer or SWPOP primer) partially overlapping strategy to remove this type of undesired products. The partially overlapping characteristic made the SWPOP primer in use anneal to the former SWPOP primer complementary site of type III product only once because the exclusive one LSC/RSC was performed in the PCR, and primed the synthesis of a novel non-target ssDNA with the $3^{\prime}$-end still completely complementary to the former SWPOP primer, which lacked perfect annealing sites for any primers used in the current round of PCR. This new ssDNA could not be converted into double-stranded form in the following HSCs and thus could not be efficiently amplified. Clearly, type III non-target products were also readily diluted out by the SWPOP primer used in the next round of PCR. In theory, the SWPOP-PCR method is equivalent to a regular specific PCR in the amplification of the target fragments and the inhibition of non-target fragments.

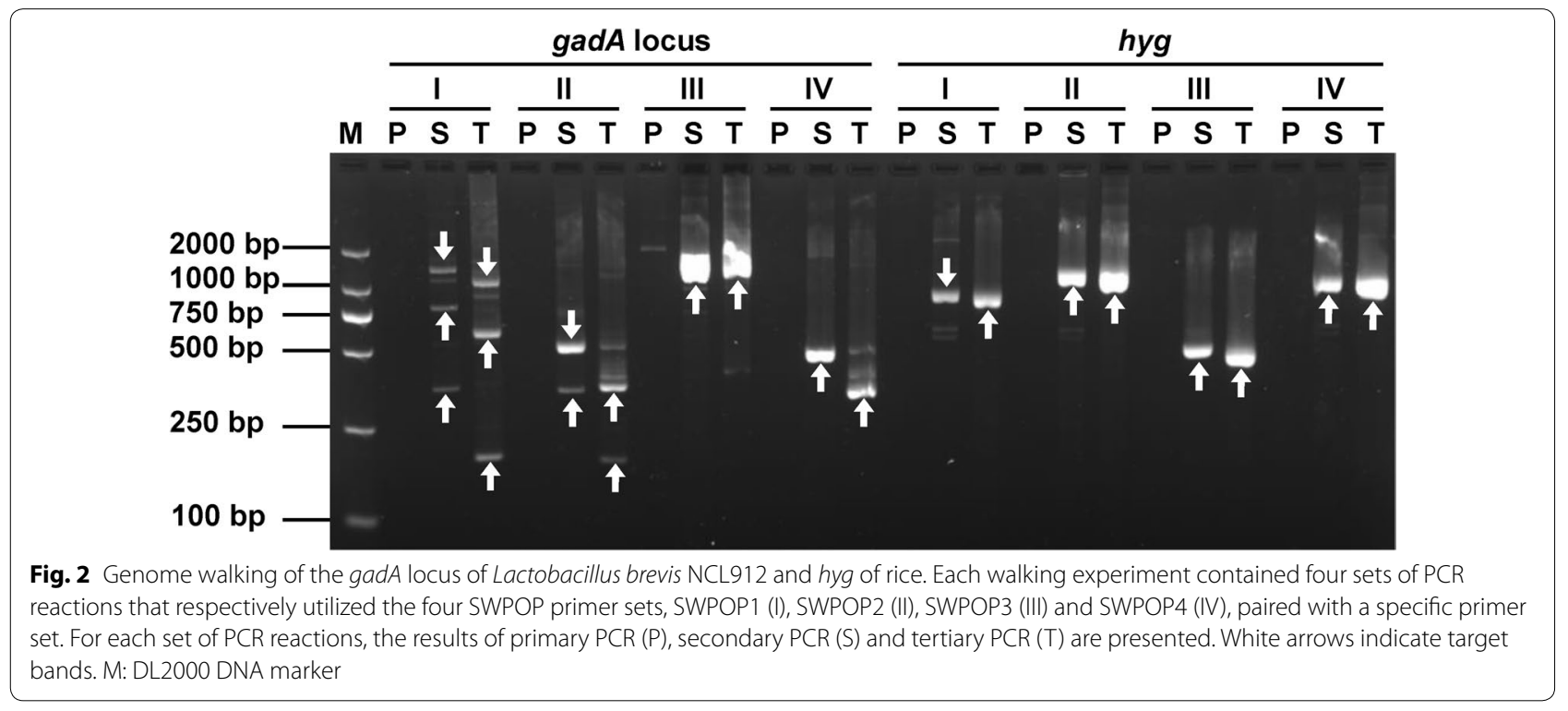


In conclusion, we have developed a novel SWPOP-PCR method for genome walking to isolate and identify the unknown DNA sequences flanking the known segments. Compared to the conventional POP-PCR, SWPOP-PCR has the merits of simplicity and efficacy due to requiring fewer primers and being suitable for making mix master. The SWPOP-PCR is an alternative of the existing genome walking methods.

\section{Abbreviations}

SWPOP-PCR: stepwise partially overlapping primer-based PCR; POP-PCR: partially overlapping primer-based PCR; gadA: glutamate decarboxylase gene; hyg: hygromycin gene; L. brevis NCL912: Lactobacillus brevis NCL912; SWPOP-P, SWPOP-S, and SWPOP-T: stepwise partially overlapping primer for primary, secondary, and tertiary PCR, respectively; SP-P, SP-S, and SP-T: specific primer for primary, secondary, and tertiary $P C R$, respectively; $T_{m}$ : melting temperature; HSC: high-stringency cycle; LSC: low-stringency cycle; RSC: reduced-stringency cycle; ssDNA: single-stranded DNA.

\section{Authors' contributions}

$\mathrm{HL}$ and $\mathrm{KC}$ designed experiments and wrote the manuscript. $\mathrm{KC}$ designed the primers. KC, QW and XS performed the PCR experiments. SW, HW and LN carried out the Agarose gel electrophoresis experiments and analyzed the data. All authors read and approved the final manuscript.

\section{Author details}

${ }^{1}$ State Key Laboratory of Food Science and Technology, Sino-German Joint Research Institute, Nanchang University, Nanchang 330047, Jiangxi, China.

${ }^{2}$ College of Life Science and Engineering, Northwest Minzu University, Lanzhou 730030, Gansu, China.

\section{Acknowledgements}

We thank Shaobo Li for providing genomic DNA sample of rice.

\section{Competing interests}

The authors declare that they have no competing interests.

\section{Availability of data and materials}

The datasets supporting the conclusions of this article are included within the article.

\section{Consent for publication}

Not applicable.

\section{Ethics approval and consent to participate}

Not applicable.

\section{Funding}

This study was funded by the National Natural Science Foundation of China (Grants 31570070 and 21566023) and Jiangxi Provincial Department of Science and Technology (Grants 20171BCB23019 and 20153BCB23034).

\section{Publisher's Note}

Springer Nature remains neutral with regard to jurisdictional claims in published maps and institutional affiliations.

Received: 10 January 2018 Accepted: 4 May 2018

Published online: 09 May 2018

\section{References}

Acevedo JP, Reyes F, Parra LP, Salazar O, Andrews BA, Asenjo JA (2008) Cloning of complete genes for novel hydrolytic enzymes from Antarctic sea water bacteria by use of an improved genome walking technique. J Biotechnol 133(3):277-286

Arnold C, Hodgson IJ (1991) Vectorette PCR: a novel approach to genomic walking. PCR Methods Appl 1(1):39-42

Bae JH, Sohn JH (2010) Template-blocking PCR: an advanced PCR technique for genome walking. Anal Biochem 398(1):112-116

Deng J, Wei M, Yu B, Chen Y (2010) Efficient amplification of genes involved in microbial secondary metabolism by an improved genome walking method. Appl Microbiol Biotechnol 87(2):757-764

I wahana H, Tsujisawa T, Katashima R, Yoshimoto K, Itakura M (1994) PCR with end trimming and cassette ligation: a rapid method to clone exon-intron boundaries and a 5'-upstream sequence of genomic DNA based on a CDNA sequence. PCR Methods Appl 4(1):19-25

Ji J, Braam J (2010) Restriction site extension PCR: a novel method for highthroughput characterization of tagged DNA fragments and genome walking. PLOS ONE 5(5):e10577

Jones DH, Winistorfer SC (1992) Sequence specific generation of a DNA panhandle permits PCR amplification of unknown flanking DNA. Nucleic Acids Res 20(3):595-600

Kotik M (2009) Novel genes retrieved from environmental DNA by polymerase chain reaction: current genome-walking techniques for future metagenome applications. J Biotechnol 144(2):75-82

Leoni C, Gallerani R, Ceci LR (2008) A genome walking strategy for the identification of eukaryotic nucleotide sequences adjacent to known regions. Biotechniques 44(2):229-235

Leoni C, Volpicella M, Placido A, Gallerani R, Ceci LR (2010) Application of a genome walking method for the study of the spinach Lhcb1 multigene family. J Plant Physiol 167(2):138-143

Leoni C, Volpicella M, De Leo F, Gallerani R, Ceci LR (2011) Genome walking in eukaryotes. Febs J 278(21):3953-3977

Li H, Li W, Liu X, Cao Y (2013) gadA gene locus in Lactobacillus brevis NCL912 and its expression during fed-batch fermentation. FEMS Microbiol Lett 349(2):108-116

Li H, Ding D, Cao Y, Yu B, Guo L, Liu X (2015) Partially overlapping primer-based PCR for genome walking. PLoS ONE 10(3):e0120139

Liu YG, Chen Y (2007) High-efficiency thermal asymmetric interlaced PCR for amplification of unknown flanking sequences. Biotechniques 43(5):649-656

Liu YG, Whittier RF (1995) Thermal asymmetric interlaced PCR: automatable amplification and sequencing of insert end fragments from P1 and YAC clones for chromosome walking. Genomics 25(3):674-681

Luo P, Su T, Hu C, Ren C (2011) A novel and simple PCR walking method for rapid acquisition of long DNA sequence flanking a known site in microbial genome. Mol Biotechnol 47(3):220-228

Mueller PR, Wold B (1989) In vivo footprinting of a muscle specific enhancer by ligation mediated PCR. Science 246(4931):780-786

Ochman H, Gerber AS, Hartl DL (1988) Genetic applications of an inverse polymerase chain reaction. Genetics 120(3):621-623

Parker JD, Rabinovitch PS, Burmer GC (1991) Targeted gene walking polymerase chain reaction. Nucleic Acids Res 19(11):3055-3060

Parks CL, Chang LS, Shenk T (1991) A polymerase chain reaction mediated by a single primer: cloning of genomic sequences adjacent to a serotonin receptor protein coding region. Nucleic Acids Res 19(25):7155-7160

Reddy PS, Mahanty S, Kaul T, Nair S, Sopory SK, Reddy MK (2008) A highthroughput genome-walking method and its use for cloning unknown flanking sequences. Anal Biochem 381(2):248-253

Rosenthal A, Jones DSC (1990) Genomic walking and sequencing by oligo-cassette mediated polymerase chain reaction. Nucleic Acids Res 18(10):3095-3096

Spalinskas R, Van den Bulcke M, Van den Eede G, Milcamps A (2013) LT-RADE: an efficient user-friendly genome walking method applied to the molecular characterization of the insertion site of genetically modified maize MON810 and rice LLRICE62. Food Anal Methods 6(2):705-713

Tan G, Gao Y, Shi M, Zhang X, He S, Chen Z, An C (2005) SiteFinding-PCR: a simple and efficient PCR method for chromosome walking. Nucleic Acids Res 33(13):e122

Terauchi R, Kahl G (2000) Rapid isolation of promoter sequences by TAIL-PCR: the 5'-flanking regions of $\mathrm{Pal}$ and Pgi genes from yams (Dioscorea). Mol Gen Genet 263(3):554-560 
Thirulogachandar V, Pandey P, Vaishnavi CS, Reddy MK (2011) An affinity-based genome walking method to find transgene integration loci in transgenic genome. Anal Biochem 416(2):196-201

Trinh Q, Shi H, Xu W, Hao J, Luo Y, Huang K (2012a) Loop-linker PCR: an advanced PCR technique for genome walking. IUBMB Life 64(10):841-845

Trinh Q, Xu W, Shi H, Luo Y, Huang K (2012b) An A-T linker adapter polymerase chain reaction method for chromosome walking without restriction site cloning bias. Anal Biochem 425(1):62-67

Tsuchiya T, Kameya N, Nakamura I (2009) Straight walk: a modified method of ligation-mediated genome walking for plant species with large genomes. Anal Biochem 388(1):158-160

Wang S, He J, Cui Z, Li S (2007) Self-formed adaptor PCR: a simple and efficient method for chromosome walking. Appl Environ Microbiol 73(15):5048-5051
Wang Z, Ye S, Li J, Zheng B, Bao M, Ning G (2011) Fusion primer and nested integrated PCR (FPNI-PCR): a new high-efficiency strategy for rapid chromosome walking or flanking sequence cloning. BMC Biotechnol 11:109

Wang H, Yao T, Cai M, Xiao X, Ding X, Xia L (2013) A genome walking strategy for the identification of nucleotide sequences adjacent to known regions. Biotechnol Lett 35(2):279-284

Yan Y, An C, Li L, Gu J, Tan G, Chen Z (2003) T-linker-specific ligation PCR

(T-linker PCR): an advanced PCR technique for chromosome walking or for isolation of tagged DNA ends. Nucleic Acids Res 31(12):e68

\section{Submit your manuscript to a SpringerOpen ${ }^{\circ}$ journal and benefit from:}

- Convenient online submission

- Rigorous peer review

- Open access: articles freely available online

- High visibility within the field

- Retaining the copyright to your article

Submit your next manuscript at $\boldsymbol{\nabla}$ springeropen.com 